\title{
Prática da enfermeira no Programa de Saúde da Família: a interface da vigilância da saúde versus as ações programáticas em saúde
}

\author{
The nurse's role in the Family H ealth Program: \\ an interface between health surveillance and health \\ program actions
}

M aristella Santos N ascimento 1

$\mathrm{M}$ aria Angela Alves do $\mathrm{N}$ ascimento 2

\footnotetext{
1 Departamento de Saúde. Universidade Estadual do Sudoeste da Bahia, UESB, Campus de Jequié. Av. José M oreira Sobrinho $s / n$, Jequiezinho, 45206-190, Jequié BA. maristellamenezes@ bol.com.br 2 Universidade Estadual de Feira de Santana eNUPISC/UEFS.
}

Abstract This study analyzes the nurse's practice in the Program of Family Health (PSF) in the municipal district of Jequié (BA), comprising the conceptions attributed to it, identifing activities and pointing out limits, progress and perspectives. A qualitative research, where techniques and data collection have been semi-structured interview and observation, and analysis of documents. Data analysis has been hermeneutic dialectics. The results made evident that the PSF is a strategy of ( re) orientation of the model of attention to the health and a means of consolidation of the U nique System of $\mathrm{H}$ ealth. The nurse's practice are aid, management, instruction. Throughout its performance it uses a given technological organization of achievement in health, adjusted by pronounced experience of promotion, prevention and offence of illnesses, recovery and rehabilitation of health of population groups, and intervention upon the family, that has results in the recombination of basic aid and reorganization of the local health system. As limits appear difficulties to assure the user's access to services of semi-and high complexity and to set up the system of references and counter-reference; as improvements, stands out introductive training and there are prospects of increase in covering of the PSF in the hierarchizing of the local system.

Key words Nurse's practice, M odel of attention, Program of Family Health
Resumo 0 estudo analisa a prática da enfermeira no Programa de Saúde da Família (PSF) em Jequié (BA); compreende as concepções sobre o PSF; identifica as atividades e aponta limites, avanços e perspectivas. Pesquisa qualitativa, em que as técnicas de coleta de dados são a entrevista semi-estruturada, a observação e a análise de documentos. 0 método de análise de dados foi a hermenêutica dialética. 0 s resultados evidenciaram que o PSF éuma estratégia de (re) orientação do M odelo de A tenção à Saúde e um caminho para consolidação do Sistema Ú nico de Saúde. As práticas das enfermeiras do PSF são assistenciais, gerenciais e educativas. Durante a sua execução utiliza uma dada organização tecnológica do trabalho em saúde, com práticas articuladas de promoção, prevenção de doenças e agravos, recuperação e reabilitação da saúde de grupos populacionais e intervenções sobre a família, o que tem re sultado na reestruturação da atenção básica ea reorganização do sistema local de saúde. Como limites apresentam-se dificuldades em assegurar 0 acesso dos usuários aos serviços de média e alta complexidade e estabelecer 0 sistema de referência e contra-referência; como avanços, destaca-se a participação no treinamento introdutório, e têm perspectivas 0 aumento da cobertura do PSF no município e a hierarquização da rede local. Palavras-chave Prática de enfermeira, M odelo de atenção, Programa de Saúde da Família 


\section{Introdução}

A Constituição Federal Brasileira de 1988 materializou o ideário reformador de construção do Sistema Ú nico de Saúde - SUS, quando propôs um papel estratégico à conformação do Sistema de Saúde para garantir acesso universal ao sistema, superando propostas existentes e estabelecendo um novo conceito de saúde definido como direito, além de contemplar os níveis de atenção em saúde, o que permitiu que uma nova configuração nos serviços de saúde fosse possível para priorizar ações de caráter coletivo e preventivo sem detrimento das ações de cunho individual e curativo, até então predominantes.

A regulamentação do SUS, através das Leis Orgânicas da Saúde 8.080/90 e 8.142/90, estabelece princípios e direciona a implantação de um modelo de atenção à saúde que priorize a descentralização, universalidade, integralidade da atenção e o controle social, ao tempo em que incorpora em sua organização o princípio da territorialidade para facilitar o acesso das demandas populacionais aos serviços de saúde (Brasil, 1990).

Estas conquistas representam as fases de implementação dos princípios e diretrizes do SUS e requerem mudanças institucionais para incorporar, na prática, as novas formas de gestão para a construção de um modelo assistencial fundamentado na Vigilância à Saúde, a partir da (re) orientação da atenção básica para (re) organizar a saúde em um contexto de maior complexidade até a Gestão Plena do Sistema M unicipal de Saúde através da implantação do Programa de Saúde da Família (PSF), com o objetivo de organizar a prática assistencial.

O PSF, criado em 1994 pelo M inistério da Saúde, surgiu, na qualidade de estratégia setorial de reordenação do modelo de atenção à saúde, como eixo estruturante para reorganização da prática assistencial, no sentido de imprimir uma nova dinâmica nos serviços de saúde e estabelecer uma relação de vínculo com a comunidade, humanizando esta prática direcionada à vigilância à saúde, na perspectiva da intersetoralidade (Brasil, 1994).

Desta forma, o Programa propõe organizar as práticas nas suas Unidades Básicas de Saúde (UBS), evidenciando o caráter multiprofissional e interdisciplinar das Equipes de Saúde da Família (ESF), com a prestação de atendimento integral nas especialidades básicas de saúde, numa base territorial delimitada com garantia de serviços de referências à saúde para os níveis de mai or complexidade, possibilitando o reconhecimento da saúde como um direito de cidadania, ao estimular a organização da comunidade e buscar 0 aprimoramento da participação e do controle social da população na área da saúde.

0 interesse em compreender, numa perspectiva crítica/analítica, a efetividade da prática das enfermeiras nas equipes de saúde da família é justificado pela sua relevância social ao surgir como prática social para legitimar-se no contexto político social do setor saúde, de modo a contribuir para a construção de um projeto político para a Enfermagem, por acreditar que essa prática poderá facilitar a construção de novos saberes, e por entendê-la na perspectiva da produção de novos conhecimentos no sentido de elaborar proposições para a efetivação desse modelo de atenção.

N este estudo, investigamos qual (ais) a(s) concepção(ões) da enfermeira sobre o Programa Saú de da Família, e como vem se processando a prática da enfermeira nas equipes da saúde da família no município de Jequié (BA), tendo como objetivos: analisar a prática da enfermeira no PSF, considerando os agentes, os instrumentos, o objeto e a finalidade do trabaIho em saúde no município em foco no período de 1999-2002; identificar as atividades desenvolvidas pelas enfermeiras e apontar avanços, limites e perspectivas do PSF no M unicípio de equié.

\section{Referencial Teórico}

\section{Processo de trabalho da enfermagem como prática social a partir da década de 1990}

Para estudarmos a prática da enfermeira no Programa de Saúde da Família torna-se necessário abordarmos como tem se processado a inserção desta trabalhadora nas políticas de saúde, para assim compreender o projeto que está em construção na sociedade brasileira. A partir da década de 1990, ficou evidenciado a inserção da enfermeira com uma maior participação no mercado de trabal ho nas áreas de gestão, assistência, docência e pesquisa, entre outras práticas.

Há de se questionar se esta profissional vem atuando na perspectiva de acompanhar as transformações pelas quais passa a sociedade, decorrentes da política nacional de saúde que exige 
cada vez mais trabalhadores comprometidos com competência técnica, ética, comunicacional e política, para a implantação e organização dos serviços de saúde no exercício da prática da Enfermagem. Esta prática vista como resultante da expressão dos modos de organização social, integra-se às práticas dos outros trabalhadores de saúde como um coletivo que responde pela produção de serviços de saúde. Portanto, a Enfermagem é uma prática social que está determinada historicamente.

Desta forma, a prática da enfermeira é parte de um processo coletivo de trabalho que tem como finalidade produzir ações de saúde, caracterizando-se por um saber específico, com ações contínuas e articuladas com os demais membros da equipe, na construção dos objetos comuns de trabalho no setor saúde (Almeida \& Rocha, 1989).

Ao longo do tempo, a prática da enfermeira tem se constituído na organização do processo de trabalho de Enfermagem no modelo clínico de atenção, tendo como objeto de trabalho a cura dos corpos individuais por meio do cuidado, com processo semelhante ao trabalho do médico, pautado no modelo liberal privatista. Este material iza-se em distintas formas de organização do trabalho que vão desde o consultório ao ambulatório, cujo ápice da hierarquização tecnológica é o hospital.

Mendes-Gonçalves (1994) afirma que o trabal ho em saúde se desenvolve a partir de duas vertentes distintas, embora não excludentes: a epidemiologia ea clínica. Elas dão origem aos modelos de atenção em saúde e ao processo de trabal ho que a saúde coletiva tem adotado em diversas formas de organização, sen do a mais recente a concepção de serviços de saúde com o enfoque na atenção primária, atuando nas ações de controle do meio ambiente físico, biológico e social, ao lado do assistencial a grupos populacionais, priorizando o "enfoque de risCo", o alvo de ações programáticas.

A proposta de construção do SUS tem propiciado mudanças no âmbito dos serviços de saúde e do modelo de atenção em saúde. N este sentido, a prática da enfermeira passa por uma série de transformações, deslocando a sua atuação profissional predominantemente da área curativa, individualizada, vinculada às instituições hospitalares para a produção de serviços em unidades básicas de saúde com ênfase nas ações de promoção e prevenção de saúde em bases coletivas, sendo a equipe de saúde a unidade produtora destas ações.
Entendemos que a enfermeira para atuar no Programa de Saúde da Família deverá incorporar alguns conceitos aplicáveis ao processo de trabalho no setor saúde, na qualidade de membro da equipe de uma unidade produtora de serviços de saúde, responsável por uma demanda social de uma área adscrita.

0 processo de trabalho é então entendido como um conjunto de saberes, instrumentose meios, tendo como sujeitos profissionais que se organizam para produzirem serviços de modo a prestarem a assistência individual e coletiva para obtenção de produtos e resultados decorrentes de sua prática ( $M$ endes-Gonçalves, 1994).

Assim, para o agir profissional, a enfermeira deve utilizar os meios e instrumentos como elementos de aproximação ao objeto de trabaIho relacionado aos saberes específicos (não materiais) e à tecnologia material. Estes meios ou instrumentos devem ser organizados para atender às demandas de saúde que, por sua vez, são subordinadas às lógicas ideológicas, políticas e econômicas com repercussões nas práticas de saúde.

Nesta perspectiva, a prática da enfermeira deverá intervir através da organização do processo de trabal ho, com uma nova estratégia articulada com a equipe de saúde a fim de que cada sujeito possa desempenhar seu trabal ho como agente de transformação.

\section{Metodologia}

Trata-se de um estudo de abordagem qualitativa, numa aproximação crítica analítica, por possibilitar trabalhar com universos de significados sociais.

A pesquisa foi realizada no município de Jequié, situado no sudoeste da Bahia, tendo como cenário as onze U nidades de Saúde da Família (USF) e como sujeitos do estudo as onze enfermeiras que atuam nas respectivas equipes, denominadas de grupo I. Paralelo a esse grupo, entrevistamos informantes-chave, uma ex-coordenadora do PSF, a coordenadora atual, ambas enfermeiras, além de uma outra enfermeira, que participou da elaboração do projeto e implantação das equipes, constituindo o grupo II, totalizando14 enfermeiras. 0 estudo foi desenvolvido no período entre 1999 e 2002.

As técnicas de coleta de dados foram a entrevista semi-estruturada, a observação sistemática e análise de documentos oficiais. A en- 
trevista semi-estruturada possibilitou-nos obter informações a partir das falas das enfermeiras. As fal as foram gravadas com o consentimento das mesmas, assegurando a privacidade, 0 anonimato e sigilo absoluto sobre as declarações prestadas, atendendo à Resolução 196/96 do Conselho $\mathrm{N}$ acional de Saúde, através da assinatura do Termo de Consentimento Livre e Esclarecido.

A segunda técnica de coleta, a observação sistemática, seguiu um roteiro com o objetivo de subsidiar os aspectos considerados relevantes na observação em diferentes espaços/territórios das USF. O período de coleta de dados ocorreu entre abril e setembro de 2002.

Para a obtenção de outras informações que subsidiassem o estudo utilizamos os seguintes documentos oficiais da Secretaria M unicipal de Saúde de Jequié: Relatório da III Conferência M unicipal (2002); Relatório de Gestão - 1998, 1999, 2000 e 2001.

$\mathrm{Na}$ análise dos dados nos aproximamos do método de análise hermenêutica-dialética, uma vez que este método permite-nos construir e reconstruir a realidade através da interpretação e confronto de diversos pontos de vista dos sujeitos do estudo, estabelecendo uma articulação entre o referencial teórico e os dados empíricos obtidos nas entrevistas, observações e documentos nos possibilitando a conformação de duas categorias empíricas centrais: concepções das enfermeiras sobre o Programa de Saúde da Família e a prática da enfermeira no PSF com a interface da Vigilância da Saúde versus Ações Programáticas em Saúde. Ao destacarmos os depoimentos das entrevistadas, estas foram identificados por um número ( 1 a 14), obedecendo-se a ordem crescente de cada entrevista, acompanhado pelo grupo denominado (grupo I ou grupo II).

\section{Análise dos resultados}

\section{Concepções das enfermeiras sobre o PSF}

Ao analisarmos a concepção das enfermeiras acerca do PSF, tomamos como parâmetro os depoimentos tanto das informantes-chave (grupo II) quanto das enfermeiras do PSF (grupo I), destacados a seguir:

(...) uma proposta de "substituição das práticas" de um modelo de atenção hegemônico caracterizado pela atenção individualizada frag- mentada e desumanizada e que tem o médico e 0 hospital como o centro das atenções, por ações realizadas por uma equipe multiprofissional que presta uma "atenção integral, equânime, humanizada". (Ent.12, grupo I)

(...) uma proposta de "reorganização da atenção básica" (...) uma forma de vocêatender meIhor a clientela, dar resposta às necessidades reais da comunidade. (Ent. 13, grupo II)

Portanto, estes depoimentos (informanteschave) destacam a necessidade de reorganização dos serviços de saúde, a partir da atenção básica, com práticas substitutivas ao modelo hegemônico, de modo a promover uma assistência integral, equânime e humanizada, dando ênfase à promoção à saúde no primeiro nível de assistência, por uma equipe multiprofissional.

Por outro lado, as concepções das enfermeiras que atuam nas equipes de saúde da família (grupo I), conforme os depoimentos que se seguem, convergem com os depoimentos das informantes-chave, ao evidenciarem que o PSF é um instrumento para (re) organizar o sistema de saúde, ao funcionar como porta de entrada dos usuários neste sistema a partir da atenção básica, com a responsabilidade pela referência desses usuários para as unidades de maior complexidade.

(...) a estratégia de saúde da família "puxa a organização"; identifica no M unicípio a necessidade de "organizar o seu sistema de saúde", sendo ele a "porta de entrada", necessitando de outro nível da assistência, ela faz com que o M unicípi o possa racionalizar o si stema de atenção à saúde a nível municipal. (...) a equipe de saúde da família "trabalha com assistência básica". (Ent. 4, grupo I)

(...) é uma estratégia que veio para "reorientar o M odelo Assistencial" (...) que antes era centrado na doença (...) , o modelo está "direcionado para a família", procurando também buscar a participação da comunidade no processo saúde/doença. (Ent. 10, grupo I)

Os depoimentos dos entrevistados 4 e 10 indicam a responsabilidade das ESF em adotarem novas práticas em saúde mais consonantes com a construção de um novo modelo assistencial, não mais centrado na doença e no indivíduo nem na medicalização da assistência, com o enfoque na família, cujas práticas devem dar ênfase às ações de promoção e prevenção da saúde na perspectiva da integralidade da atenção. 


\section{- PSF : uma estratégia de (re)orientação do modelo de atenção à saúde}

Os informantes-chave compreendem o PSF como:

(...) objetivo de mudar, de "implantar o novo modelo assistencial" porque o modelo vigente no País, (...) infelizmente, ainda até hoje é o modelo assistencial médico privatista, ou então tínhamos também o modelo campanhista. (Ent. 13 , grupo II)

(...) o "reordenamento do sistema de saúde", um el emento norteador de toda organização do processo de saúde local considerando que ela é porta aberta para sistema de saúde. (Ent. 14, grupo II)

Para estas entrevistadas, o PSF permite a implantação de um novo modelo assistencial em substituição ao modelo hegemônico, através de adoção de novas práticas desenvolvidas por uma equipe multiprofissional, tendo a promoção da saúde como seu eixo central. O PSF ao ser considerado porta de entrada para o sistema local de saúde exige uma nova lógica do processo de trabalho diante do "novo modelo" que determina mudanças na política de saúde local, na perspectiva de universalizar a aten ção em saúde conforme preconiza o SUS.

Neste sentido, M endes (1996) destaca a necessidade de mudança da lógica da produção da doença para a produção da saúde, com o novo paradigma sanitário que considere outros determinantes do processo saúde-doença. M erhy e Franco (2001) destacam que é dada ao PSF a missão de mudar o modelo assistencial para a saúde, e essa mudança deve se caracterizar quando tiver um modelo que seja "usuário-centrado". Porém, o sistema de saúde local deve estar organizado de forma a atender os usuários dos serviços nos procedimentos de maior complexidade, facilitando assim o acesso da população à resolubilidade dos seus problemas de saúde.

Por trabal har com a aten ção básica, o PSF é auto-limitado na sua concepção, apresentando limites como destacam os depoimentos dos entrevistados (grupo I e grupo II).

(...) o PSF trabalha com "atenção básica", então a questão de média e alta complexidade tem que ser referendada e essa referência, não existe, muito menos, a contra referência. (Ent. 10, grupo I)

(...) o PSF, por ser uma estratégia que trabaIha essencialmente com "a atenção básica, é auto-limitado" (...) o usuário necessita de referência para níveis de maior complexidade, fato este que deve ser garantido pelos gestores municipais. (Ent. 12, grupo II)

Percebemos que o Programa limita a sua ação à resolução das necessidades de saúde por falta da definição de mecanismos formais de hierarquização da rede de serviços de saúde como forma de garantia do acesso à população a outros níveis de complexidade do sistema de saúde. Para que o PSF venha a ser operacionalizado como estratégia, os informantes-chave revelam as suas "perspectivas" diante do Programa:

(...) a perspectiva éque o PSF, na medida em que for sendo adotado pelos municípios, "substitua a lógica de trabalho" utilizada nas U BS. (Ent. 12, grupo II)

(...) "perspectivas de" implantar mais equipes "atendendo até uma recomendação da III CM S". (Ent. 13, grupo II)

Observamos nestes depoimentos a preocupação com a mudança no processo de trabalho desenvolvido nas USF para uma nova lógica de organização do trabalho pautado em um novo modelo de atenção dirigido à promoção à saúde, preven ção das doenças, recuperação da saúde e reabilitação, bem como a necessidade de ampliar a cobertura do Programa.

\section{- PSF: um caminho para a consolidação do Sistema Único de Saúde}

Para analisarmos as concepções sobre o PSF no município de Jequié reportamo-nos ao processo de descentralização das ações de saúde, a partir da municipalização, em consonância com as diretrizes da política de saúde do M inistério da Saúde, que estabelece a construção de novos modelos de atenção em saúde, com vistas à consolidação do SU S, na perspectiva de superar a forma hegemônica de organização dos serviços de saúde, a partir da reconstituição do papel da rede básica.

Nos depoimentos das entrevistadas, destacamos os fragmentos das falas em que as enfermeiras compreendem o PSF como uma estraté gia de construção de um novo M odelo de Atenção, um possível caminho para a consolidação dos princípios do SUS.

(...) é um "novo M odelo de A tenção" à saúde que atua através de uma equipe mínima de profissionais de saúde em um território delimitado. Esta estratégia tem como principal objetivo "consolidar os princípios do SU S". (Ent. 4, grupo I)

Para estas entrevistadas, o PSF é uma estratégia que possi bilita a reorientação do M odelo 
de Atenção e contribui para a consolidação dos princípios do SU S a partir da mudança de visão da saúde; eao incorporar estes princípios, acreditamos que a ESF passará a atuar nas ações de promoção e proteção individual e coletiva, assim como nas ações de recuperação e reabilitação em saúde, buscando a integralidade, eqüidade e universalidade como alternativas para 0 reordenamento da oferta de serviços de saúde.

Estas concepções e práticas a serem incorporadas pelo PSF vêm se contrapor ao que pensa Barata (2001), atuação sobre indivíduos, construída a partir de propostas de cunho individual, não tem impacto suficiente para modificar os perfis epidemiológicos populacionais ainda que possam apresentar ben efícios singulares, uma vez que cremos que, ele [o PSF], poderá produzir a redução da exclusão, ao permitir o acesso das famílias, ainda que seja em situação de risco, a serviços e ações de saúde.

Os depoimentos da entrevistada e do informante-chave apontam como "limite" do PSF a dificuldade de estabelecer o mecanismo da referência e contra-referência para os serviços especializados de média e al ta complexidade, conforme retratam os depoimentos a seguir.

(...) um dos limites que encontramos no PSF é a questão de "referência e contra-referência" (...), o que dificulta 0 acompanhamento dos pacientes devido à falta de acesso aos "exames de média e alta complexidade". (Ent. 9, grupo I)

(...) não termos ainda 0 "sistema de referência e contra referência" devidamente implantado, funcionando, muitas vezes a equipe identifica o problema, "encaminha para unidade de referência de maior complexidade" etem dificuldade nesse encaminhamento ou mesmo não tem acesso a esse serviço, com isso faz com que esse "sistema de referência e contra referência seja um nó critico da implantação do PS". (Ent. 13, grupo II)

Observamos nos depoimentos, a "dificuldade" que as ESF têm ao desenvolverem a sua prática de saúde no atendimento ao usuário e referenciar para os serviços de atenção secundária e terciária. Este M unicípio tem apresentado dificuldade na sua organização e no desenvolvimento pleno do PSF, constituindo-se assim um desafio para sua superação, porque al guns serviços de média e alta complexidade se concentram nos municípios de maior poder econômico, dificultando a garantia da integralidade das ações de saúde.

A entrevistada 14, destaca que o PSF deve:

(...) buscar "oferecer de forma organizada as ações e serviços de saúde" e promover a viabili- dade no sentido de que a saúde seja entendida enquanto aquele conceito estabelecido na Constituição (...), aquelas pessoas que estão sob responsabilidade direta daquela equipe de saúde venha receber uma atenção dita integral.

Se o programa vem sendo desenvolvido nessa perspectiva cremos que deverá contribuir para a implementação do SUS local através da organização dos serviços, e para a melhoria das condições de saúde da população que passa a ter reconhecido o direito à saúde através do acesso aos serviços de saúde em uma rede hierarquizada, propiciando a integralidade da atenção.

As falas a seguir das entrevistadas revelam suas "perspectivas", bem como os seus sentimentos na adoção do PSF na melhoria da qualidade de vida da população, acreditando que "tem tudo para dar certo", acenando para o compromisso dos sujeitos sociais envolvidos no Programa e a vontade dos gestores municipais na condução do processo.

(...) tem dificuldadeno início, mas "vejo uma luz" lá adiante, que vai realmente dar certo, vai avançar; que vai melhorar mesmo que não seja a médio prazo, a curto prazo, que seja a longo prazo, mas vai acontecer eu vejo assim, mesmo com os limites com os entraves mas eu tenho assim "uma forte féque vai dar certo". (Ent. 7, grupo I)

(...) para a comunidade eu não vejo assim melhor saída, para melhorar a qualidade de vida da população é só acrescentar aí que eu acredito realmente nessa estratégia, "acredito mesmo e eu creio que pode dar certo". (Ent. 10, grupo II)

Portanto, o PSF tem se constituído em um instrumento estratégico para a (re)organização do sistema local de saúde ganhando visibilidade a partir de sua implantação, e tem permitido a consolidação do SUS e dos trabalhos desenvolvidos pela equipe:

(...) acho que "é o caminho para que o SUS seja consolidado", esse é um caminho. (Ent. 7, grupo I)

(...) as melhores possíveis, pois passada a fase de implantação temos uma de implantação dos serviços, "uma melhor consolidação dos trabaIhos". (Ent. 9, grupo I)

0 depoimento do informante-chave desenha com otimismo as "perspectivas" para o PSF local, ao destacar que:

(...) as perspectivas "são boas", vai depender de "cada um de nós", de cada um de "nós enfermeiros", de cada um de nós "membros da equipe de saúde da família", de cada um de nós que for "gestor do serviço de saúde", daquele que é "con- 
selheiro" e do que é "morador de uma área adscrita" que está inserida uma estratégia de saúde da família. (Ent. 14, grupo II)

Canesqui (2001) entende a saúde como uma conquista social associada ao direito e à cidadania e um bem público que o Estado deve prover $\mathrm{e}$ regular, portanto, como uma questão social de responsabilidade coletiva, competindo aos gestores (federal, estadual e municipal), e profissionais de saúde a vontade política na defesa e garantia da saúde e fortalecimento do SUS; e os usuários desenvolverem a co-responsabilidade no controle social do seu direito à vida.

Acreditamos que o PSF pode viabilizar esta proposta e neste sentido visualizamos al gumas possíveis saídas na reorientação do modelo de atenção com as mudanças nas práticas de saúde a partir da atuação das ESF nesta estratégia, ao comungarmos com os desejos de alguns trechos dos depoimentos dos entrevistados: é o caminho para que o SUS seja consolidado, tenho uma forte fé que vai dá certo; acredito mesmo e eu creio que pode dar certo.

\section{Prática da enfermeira no Programa de Saúde da Família: a interface da vigilância da saúde versus as ações programáticas em Saúde}

Ao buscarmos compreender como tem se organizado a prática da enfermeira no PSF no município de Jequié, identificamos que essa prática é caracterizada pelas ações programáticas e de Vigilância da Saúde desenvolvidas por essa trabalhadora no âmbito das U nidades de Saúde da Família.

No sentido de analisarmos mais detal hadamente esta categoria, a subdividimos em duas partes por compreendermos que elas se articulam entre si, fundamentando a essência do processo de trabal ho da enfermeira do PSF no município de Jequié.

\section{- Vigilância da saúde: o modelo da redefiniç̧ão da prática da Enfermeira no PSF em Jequié (BA)}

Nesta subcategoria reconhecemos que o PSF tem como uma das propostas para reorientação à saúde o modelo da vigilância à saúde. 0 município de Jequié, ao implantar o PSF, buscou assumir as diretrizes do SU S na perspectiva de construção do novo modelo de atenção, tendo a vigilância à saúde como eixo norteador da reorganização da atenção básica de saúde, para garantir 0 atendimento integral e facilitar o acesso dos usuários aos diversos níveis de atenção através de uma rede de serviços de saúde hierarquizada e regionalizada.

Os depoimentos dos informantes-chave reafirmam a necessidade da implantação desse modelo conforme os relatos a seguir:

(...) eu compreendo quea ESF uma forma para implantação do "M odelo de Vigilância à Saúde" e Consolidação do SUS. (Ent. 12, grupo II)

(...) a proposta de saúde da família veio justamente pensando no modelo assistencial alternativo é o "modelo de vigilância à saúde". (Ent. 13 , grupo II)

A ênfase dada nas falas das entrevistadas à vigilância à saúde a caracteriza como o modelo assistencial capaz de responder às necessidades de saúde da população adscrita, por contemplar em sua configuração os elementos que dão aporte à prática das equipes de saúde das famílias. Os depoimentos das entrevistadas que atuam nas ESF convergem entre si e com os depoimentos dos informantes-chave, ao afirmarem que o PSF é uma estratégia de mudança, direcionada ao modelo de atenção da vigilância à saúde:

(...) houve uma descentralização da saúde, a municipalização da saúde e com isso a mudança (...) dos modelos de saúde dos modelos assi stenciais, os programas implantados; primeiro foi 0 PACS, depois disso surgiu essa nova estratégia que foi a PSF visando "ao novo modelo da vigilância à saúde". (Ent. 5, grupo I)

(...) é uma estratégia muito importante na estruturação(...), "novo modelo de atenção da vigilância à saúde", voltado ao indivíduo, à família eà comunidade. (Ent. 7, grupo I)

A vigilância à saúde configura uma prática de saúde que articula operações para o enfrentamento de situações de saúde ao identificar riscos, danos e seqüelas que incidem sobre indivíduos, famílias, ambientes coletivos, grupos sociais e meio ambiente, de modo a apresentar intervenções que promovam e preservem a saúde, como o estabelecimento do planejamento e programação local de saúde.

O PSF, ao incorporar o modelo da vigilância à saúde, deverá propiciar a reorganização dos serviços de saúde, valorizando a atenção primária como o primeiro nível do sistema, dando ênfase à promoção e prevenção, sem descuidar do tratamento e da reabilitação, com atendimento de forma integral, buscando a resolubilidade dos problemas de saúde. No entanto, Franco e M erhy (1998) evidenciam algumas 
críticas acerca da vigilância à saúde ao valorizar a epidemiologia em detrimento da clínica, enfatizando que o problema deste modelo encontra-se no processo de trabalho, restringindo-se à produção de procedimentos e não na produção do cuidado da cura, e que é preciso reorganizar o trabalho dos profissionais de saúde, atuando nos seus processos decisórios da produção de saúde.

0 informante-chave (grupo II) complementa em seu depoimento a forma de operacionalizar o trabal ho das ESF, enfocando o planejamento como ferramenta necessária para elaboração do plano de ação, conforme destaque do relato a seguir:

(...) no PSF você tem uma equipe trabalhando junto (...), em uma área adscrita (...), há uma articulação entre a comunidade e a equipe de saúde (...), a comunidade é vista como partícipe do processo de trabalho da unidade (...), trabalhado através de um "planejamento" (...), são el encados os problemas e priorizados, e as ações são implementadas de acordo com as reais necessidades da população. (...) os problemas que (...) são microlocalizados podendo identificar as áreas de risco e os fatores de riscos que interferem justamente na vida daquela população. (Ent. 13, grupo II)

Este depoimento evidencia a necessidade das ESF atuarem em áreas adscritas, com famílias cadastradas, com a identificação das áreas de risco para então elaborarem um planejamento das ações, com a participação da comunidade, desenvolvendo a programação local de saúde utilizada como um instrumento da gerência, que possi bilita a reorganização das práticas de saúde direcionadas aos problemas priorizados em conjunto.

A entrevistada e o informante-chave abordam a importância da delimitação das áreas de abrangência das ESF, através da territorialização, para permitir conhecer as condições de vida das pessoas e identificar os problemas de saúde da área, bem como para realizar o planejamento das ações de saúde, conforme os destaques a seguir:

(...) a gente tem a compreensão quanto ao "território" que, com a implantação do PSF, a gente vai delimitar uma área para trabalhar com essas famílias, que são as famílias adscritas - que é a "territorialização"; no território a gente vê (...) o perfil epidemiológico (...), as condições das pessoas, condiç̧ões de vida das pessoas; com isso nós vamos identificar os problemas existentes em cada família, fazer o diagnóstico (...), vai favore- cer para traçar ações, "planejar ações de saúde". (Ent. 6, grupo I)

(...) atua no "território delimitado", isso facilita o trabalho, porque a ESF passa a conhecer a população onde vai atuar a "população adscrita" (...), quais os problemas que ela tem enfrentado (...), esses problemas passam a ser "microlocalizados", podendo "identificar as áreas de risco" e os fatores de risco que interferem na vida daquela população. (Ent. 13, grupo II)

A convergência entre os depoimentos da entrevistada e do informante-chave vislumbra a facilidade de trabal har com uma área de abrangência delimitada, com famílias adscritas, identificação dos problemas de saúde, com o planejamento e programação das ações de saúde, operacionalizando a prática das ESF, de acordo com as necessidades de saúde da população daquela área.

\section{- Ações programáticas - o concreto da prática da enfermeira no PSF}

As unidades de saúde da família no município de Jequié são organizadas tendo como aportes a tecnologia, a epidemiologia e a clínica, através de um conjunto de ações básicas de saúde dirigidas a grupos populacionais com base nas ações programáticas. As enfermeiras desenvolvem ações de caráter individual, de controle da demanda espontânea e oferta organizada.

O percentual de cobertura do PSF no município é de $28 \%$ (Jequié, 2001), o que não tem permitido a inclusão de todos os grupos populacionais em situação de risco a este Programa. D esta forma, percebemos a necessidade da implantação de novas equipes visando ampliar este percentual conforme o depoimento da entrevistada.

(...) já começamos com "um número enorme de famílias", e até hoje nós ainda temos uma "demanda um pouco reprimida"; é difícil para a gente estar sempre tentando buscar melhorar (...) através de reuniões com a Secretaria de Saúde, também com os líderes comunitários. (Ent. 2, grupo)

O modelo de ações programáticas no Brasil foi instituído para possibilitar o aumento da cobertura de atendimento aos grupos de risco na perspectiva de promoção, prevenção e recuperação da saúde desses grupos. Acreditamos que a enfermeira, através da consulta de enfermagem, pode proporcionar a ampliação do atendimento na rede básica de saúde, por meio da 
oferta de ações programáticas. Os depoimentos das entrevistadas convergem com as falas dos informantes-chave, ao discorrerem sobre as atividades desenvolvidas pelas enfermeiras.

(...) "consulta de enfermagem, sala de espera", a gente faz "reuniões com a comunidade, visita domiciliar, TRO", acompanhamento em sala de "curativo, imunização", tirando dúvida das auxiliares e dos outros funcionários se necessário (...), "acompanhamento da criança, saúde da mulher, atendimento ao hipertenso, diabético", ao idoso e também acompanhamento em domicílio de pacientes acamados (...), atividade extramuro (...), sala de espera, nós temos também "reunião de equipe" uma vez por semana junto com os ACS (...), "palestra também nas escolas". (Ent.1, grupo I)

(...) as "principais atividades" realizadas podem ser assim resumidas: "atividades de supervisão" direta e indireta do trabalho das equipes; avaliação e controle da produção de serviços e indicadores de saúde; "apoio administrativo e técnico; reuniões" com as equipes e comunidades; confecção de relatórios; socialização das informações acerca da produção de servi ços e indicadores de saúde; "atividades de programação e planejamento com as equipes". (Ent. 12, grupo II)

Percebemos, a partir destas falas, que o modelo de organização do processo de trabalho das ESF é pautado nas ações programáticas em saúde, com práticas, predominantemente, voltadas à assistência. No entanto, podemos extrair al guns componentes da vigilância à saúde como acolhimento, sala de espera, sistema de informação, atividades extramuros, reuniões da comunidade e planejamento.

Apesar de compreendermos que a ação programática constitui uma ferramenta útil e coerente com as noções de território e os problemas de saúde no modelo de vigilância à saúde, comungamos com Campos (1997) ao considerar que estas ações têm limitação em sua prática por utilizar apenas a epidemiologia para perceber os determinantes do processo saúdedoença, sem observar a subjetividade e a individualidade dos usuários como valores na percepção dos problemas de saúde, uma vez que a ação programática e a epidemiologia impedem, na maioria das vezes, o acesso do cidadão aos serviços de saúde.

Percebemos então que as enfermeiras e os informantes-chave entrevistados identificam na prática da enfermeira as atividades de âmbito "assistencial", em que o modelo de organização proposto é o de ações programáticas em saúde dirigidas à atenção integral à saúde da mulher, da criança e do adolescente, do adulto e atenção domiciliar.

As enfermeiras que trabalham nas ESF em Jequié, ao adotarem as ações programáticas como proposição para organizar sua prática, deverão expressar o projeto histórico da saúde coletiva. Deste modo, esta prática deve ser flexibilizada para adaptar-se às demandas sociais por serviços de saúde, uma vez que elas parecem não dar conta em atender aos usuários da área em suas necessidades de saúde, ficando assim, uma demanda reprimida no atendimento em saúde.

As Visitas Domiciliares (VD) são realizadas por todos os integrantes da ESF; a enfermeira sempre se faz acompanhar dos ACS e/ou Auxiliar de Enfermagem nestas visitas. As enfermeiras realizam mensalmente $V D$ dirigidas a todos os grupos populacionais, buscando atender as diretrizes estabelecidas para esta atividade no PSF; defendemos, portanto, que seja realizada sempre que houver uma sinalização de sua necessidade pelo ACS, assim como pela percepção da enfermeira quando do atendimento na USF.

A fala da informante-chave coaduna com a da entrevistada ao relatarem como são realizadas visitas domiciliares às famílias:

(...) "faço visita domiciliar"; são dois dias de visita domiciliar, cada dia com oito visitas, não só às pessoas acamadas mas àquelas pessoas que são resistentes às vacinas; àquelas pessoas que são resistentes, aos hipertensos que são resistentes e não querem tomar a medicação; principalmente às pessoas com problemas na área social; higiene para todos as pessoas que são detectados problemas através dos agentes comunitários de saúde que necessitem de orientação. (Ent. 5, grupo I)

(...) "as visitas domiciliares" que os enfermeiros fazem aos grupos específicos ou também a um caso individual, um faltoso do programa de tuberculose daquela área é visitado em um primeiro momento pelo próprio agente, a partir de uma própria orientação da enfermeira, mas se sentindo a necessidade ela também realiza uma visita específica. (Ent. 14, grupo II)

Contudo, M erhy e Franco (2001) ressaltam que a visita domiciliar significa uma excessiva intromissão do Estado na vida das pessoas, limitando sobremaneira seu grau de privacidade e liberdade. N esta perspectiva, entendemos que as VD devem ser direcionadas para situações estritamente necessárias ao acompanhamento das famílias, ou quando as famílias as solicitarem. 
U ma segunda prática identificada neste estudo desenvolvida pela enfermeira no PSF éa "gerencial", destacando a coordenação da USF, a supervisão dos auxiliares de Enfermagem aos Agentes Comunitários de Saúde, as ações de vigilância epidemiológica, controle de material, medicamento e pessoal, reunião de equipes, programação local.

A "prática gerencial", destaca Junqueira (1990), (...) requer conhecimentos e habilidades que passam pelas dimensões técnica, administrativa, política e psicossocial. Estas dimensões possuem si gni ficados próprios permitindo caracterizar não um único estilo de gerência eficaz, mas qualidades que devem permear a ação do gerente.

Porém, para atuar na gerência das USF énecessário desenvolver um conjunto de habilidades para conseguir al cançar os objetivos traçados pela equipe ao estabelecer o plano de ação local. Almeida e Rocha (1989) resgatam a gerência como um instrumento de trabalho nas práticas sanitárias; portanto, o PSF pode ser uma atividade-meio, que tem os objetivos de articular e organizar o processo de trabalho das ESF. Assim, a gerência éuma prática inerente ao processo de trabalho das equipes de saúde da família que deveria ser responsabilidade de todos os membros da equipe e que é comumente responsabilidade das enfermeiras que assumem essa atribuição na coordenação das USF :

(...) uma das primeiras "atividades" é como "coordenadora de unidade" de saúde da família, onde a gente tem como objetivo principal o funcionamento básico da unidade, "o planejamento, a organização de todo o funcionamento da unidade" (...), a "de supervisão" que além da supervisão dos próprios funcionários da unidade que são os auxiliares de Enfermagem e agentes administrativos, estamos supervisionando todas as atividades, sala de curativo, vacinação, injeção e na parte de orientação e da "supervisão dos ACS". (Ent. 9, grupo I)

(...) a "coordenação da USF" onde a gente trabalha com toda "parte burocrática da unidade", planejamento, solicitação de materiais, me dicações, a questão de pessoal, freqüência, enfim todas as questões administrativas que en volvem a U SF, além de fornecer dados para o sistema de informação. (Ent. 10, grupo I)

U ma das problemáticas vivenciada pelas enfermeiras das ESF em relação às condições de trabalho e manutenção da unidade para atuação das equipes retrata as "dificuldades" das ESF no processo de trabalho da unidade. Para as ESF atuarem adequadamente devem ser oferecidas condições mínimas necessárias ao bom desenvolvimento das ações de saúde, propiciando o al cance dos objetivos traduzidos pela pactuação da atenção básica realizada entre os gestores federal, estadual e municipais de melhorar os indicadores de saúde locais.

A rotatividade dos trabal hadores de saúde da ESF, em especial o médico, tem sido um fator "limitante" do PSF, uma vez que o programa não tem conseguido fixar este profissional no município. Por sua vez, essa categoria, muitas vezes, não tem perfil para o trabalho no âmbito da saúde coletiva conforme o depoimento da entrevistada:

(...) "rotatividade de profissionais" é muito grande, ainda encontramos profissionais que não têm perfil para trabalhar nessa estratégia. (Ent. 4, grupo I)

A creditamos que este limite se deve à formação acadêmica desses profissionais - os médicos em sua maioria, que são formados no modelo flexneriano, para atender as especialidades e não aos problemas de saúde enfrentados pela população, e à integralidade da assistência. As variações salariais e as condições de trabalho têm contribuído para o agravamento da situação de rotatividade profissional nas USF.

A inserção das ESF tem contribuído para a melhoria da situação de saúde local. N os Relatórios de Gestão (J equié, 1998 a 2001) os indicadores de avaliação da atenção básica demonstram 0 aumento das coberturas vacinais, a redução da mortalidade infantil em menores de um ano, 0 aumento na captação de gestante no primeiro trimestre de gravidez, o aumento da cobertura do aleitamento materno e o cadastramento, acompanhamento e controle dos hipertensos e diabéticos.

A "prática educativa" é entendida como parte do trabal ho da enfermeira. As ações educativas são realizadas durante a consulta de enfermagem, nas salas de espera, com grupos prioritários de gestantes, mães, adolescentes, hipertensos e diabéticos, nas USF e em reuniões comunitárias e escolas.

(...) faço "atividades educativas", como "sala de espera", reuniões com a comunidade, "reuniões educativas", reuniões para planejamento e programação das atividades, reuniões com os $A C S$, reuniões de equipe que tem todos os membros da equipe e depois tem reuniões com ACS, "capacitação dos ACS". (Ent. 2, grupo I)

Nessa fala, percebemos que a prática de educação em saúde precisa vislumbrar al gumas 
possibilidades de transformações. Para tanto, entendemos serem necessárias inovações pedagógicas para permitir uma maior aproximação com as famílias para conhecer seu modo de vida e utilizar técnicas que permitam uma participação ativa na construção do conhecimento em saúde. Assim, a enfermeira tem de estar capacitada para produzir estas transformações, com vistas à promoção da autonomia dos sujeitos sociais, em busca do exercício de cidadania.

A pesar de a prática educativa realizada pelas enfermeiras das ESF se constituir em uma das atividades que vem sendo desenvolvida regularmente em algumas USF, a mesma apresenta "limites" à sua execução, uma vez que tem se processado quase que exclusivamente com uma prática pedagógica tradicional, embora já sinalize para novas abordagens através das oficinas para gestantes.

Neste sentido, corroboramos com a concepção de Freire (1979) sobre educar, ao conceber a educação como uma construção coletiva, na qual os conteúdos abordados devem estar relacionados à realidade dos sujeitos participantes do processo de educação. N esta perspectiva, as enfermeiras deverão incorporar a prática educativa como uma ação transformadora.

Um dos "avanços" ocorridos diz respeito a realização do treinamento introdutório para subsidiar as ESF no desenvolvimento de suas atividades, revelando a necessidade de capacitar os profissionais para que possam compreender o processo de trabalho nas ações e serviços de saúde por meio da identificação e análise dos elementos constitutivos de seu trabalho em saúde, e das relações daí decorrentes, resultando na promoção da saúde como produção social.

Entretanto, acreditamos ser necessário estabelecer um processo de educação permanente para suprir as deficiências da formação acadêmica dos trabalhadores que atuam no PSF, bem como as carências que surgem de acordo com os problemas de saúde da realidade local, para que a equipe, durante o processo de trabalho, envolva a comunidade e obtenha mais segurança e autonomia no desenvolvimento de novas práticas em saúde.

O PSF encontra como "limite" a formação dos recursos humanos, que requer uma mudança significativa no processo de formação nas universidades, com mudanças curriculares com a introdução de novas bases conceituais para a construção de novas práticas no sentido de responder ao novo modelo que se pretende construir.

A "prática política" tem como finalidade incentivar a formação e/ou participação ativa dos sujeitos, profissionais de saúde nos Conselhos Locais e M unicipais de Saúde. As enfermeiras, juntamente com os demais membros das ESF, vêm procurando timidamente ter uma participação social ao promoverem espaços de discussão junto das famílias e dos grupos de comunidade, possibilitando a transformação dos sujeitos sociais em sujeitos políticos, quando estes participam da elaboração da programação local e se mantêm informados através da socialização das informações.

Os Consel hos de Saúde, segundo Carvalho (1995), têm atribuições que abrangem campos de ações ou práticas, no âmbito do SU S o campo do planejamento e controle da execução da política de saúde e o campo de articulação com a sociedade, propiciando espaços de construção da cidadania.

Portanto, o Conselho é o espaço de negociação de todo o segmento organizado da sociedade, com a delegação da autoridade através da legitimação da representatividade de seus membros, que deve ultrapassar os limites da formalidade e burocracia, ganhando visibilidade com a publicização de suas deliberações e efetivamente decidir as diretrizes da política de saúde local.

No depoimento da entrevistada, visualizamos que as enfermeiras promovem a participação social da população através das reuniões comunitárias conforme destacamos a seguir:

(...) a comunidade reconhece os problemas locais e organiza sua assistência, sistematiza suas ações através do planejamento estratégico identificando problemas, viabilidade das ações, as ações que devem ser desenvolvidas; "facilita a participação social, porque a comunidade participa" desse planejamento estratégico ajudando a equipe a levantar os seus problemas. (Ent. 4, grupo I)

As reuniões são consideradas espaços privilegiados do exercício da cidadania e poderão constituir-se em um espaço de gestão col egiada para a solução de conflitos, uma vez que nela interagem atores com diferentes projetos e interesses.

Entretanto, a proposta de criação dos Conselhos Locais de Saúde aprovada na III Conferência M unicipal de Saúde do M unicípio de Jequié (CM S) não se concretizou, o que parece ser uma contradição na gestão do sistema local 
de saúde. Entendemos que a prática política poderá ser fortalecida, de modo que o controle social no M unicípio se consolide a partir da estratégia de saúde da Família.

\section{Considerações finais}

As discussões apresentadas neste estudo em relação à prática da enfermeira no PSF parecem estar consonantes com o momento histórico e social das transformações que perpassam a sociedade contemporânea, a depender do ol har de cada ator social que participa do processo de transformação social, o que nos leva a refletir sobre a saúde da família como um caminho para a consolidação do SU S e uma estratégia de (re)orientação do modelo de atenção a saúde no Município.

A compreensão do PSF para as enfermeiras é de que esta é uma estratégia de reorientação de um novo modelo assistencial que dá ênfase à vigilância à saúde. 0 Programa encontra-se implantado em áreas rurais e periféricas da cidade em situações de extrema pobreza. O PSF local trabalha com delimitação da área, e população adscrita, buscando atender a demanda espontânea e oferta organizada, identificando os problemas de saúde para intervir na realidade em saúde através da ferramenta do planejamento estratégico situacional.

A prática da enfermeira no PSF tem como proposta de organização tecnológica a vigilância da saúde e a programação em saúde. Estes modelos buscam incorporar os determinantes sociais do processo saúde/doença da população no desenvolvimento de práticas de prevenção, promoção e recuperação da saúde dos grupos sociais das áreas adscritas com vistas à construção do novo modelo de assistência.

Neste sentido, o Programa de Saúde da Família no município vem se constituindo como um instrumento de mudanças na atenção básica de saúde, respondendo ao que coloca o novo modelo assistencial, ou seja, centrado não somente na cura da doença, mas, sobretudo, na interven ção de fatores de riscos e na incorporação de ações programáticas para a promoção da qualidade de vida das famílias sob sua responsabilidade.

A prática da enfermeira no PSF do M unicípio vem se conformando em práticas direcionadas às atividades de ordem gerenciais, assistenciais e interativas atuando no controle do processo de trabalho, no atendimento aos grupos prioritários e estimulando a participação social através de reuniões comunitárias de acordo com as necessidades de saúde da população, através das ações programáticas, priorizando os grupos de riscos.

$\mathrm{N}$ a prática gerencial, as atividades administrativas ficam sob total responsabilidade da enfermeira; quanto à prática educativa, esta tem apresentado uma evolução em sua dinâmica, existindo a necessidade se dar maior ênfase à atuação da enfermeira nas ações educativas no PSF.

Entretanto, a prática da enfermeira encontra dificuldades nas articulações intra e intersetoriais, na integralidade da atenção para a continuidade da assistência às famílias. As enfermeiras revelaram que se sentem valorizadas e têm o seu trabalho reconhecido pela comunidade, uma vez que têm mais autonomia em sua área de atuação, oportunidade em que além de utilizarem o saber clínico na prática assistencial, utilizam o saber epidemiológico em situações de risco, assim como também o enfoque educativo nas ações de promoção e preven ção à saúde.

Contudo vemos que as enfermeiras precisam repensar e analisar a sua prática a partir dos princípios que norteiam o SUS para viabilizarem as transformações necessárias, e não se mantenha a reprodução do modelo liberal privatista ou o model o racionalizador reformista. $\mathrm{N}$ a realidade, ao assegurar às enfermeiras a responsabilidade e a possibilidade de reordenarem o seu papel histórico nas instituições, énecessário que se avalie e se refaça as suas formas de organização no processo de trabalho. 


\section{Colaboradores}

MS N ascimento elaborou o artigo a partir da dissertação de mestrado em Saúde Coletiva, e teve como orientadora M AA N ascimento.

\section{Referências bibliográficas}

Almeida M CP \& Rocha JSY 1989. 0 saber da enfermagem e sua dimensão prática. Cortez, São Paulo.

Almeida M CP \& Rocha SM M 1997. Considerações sobre a enfermagem enquanto trabalho. In M CP Almeida $\&$ SM M Rocha (orgs.). 0 trabalho de enfermagem. Cortez, São Paulo.

Barata RB 2001. Os desafios da teoria e da práxis da saúde coletiva. Ciência \& Saúde Coletiva 6(1):20-21.

Brasil 1990. M inistério da Saúde. Lei no 8.080, de 19 de setembro de 1990. Brasília-DF; Diário O ficial da União.

Brasil 1990b. M inistério da Saúde. Lei no 8.142, de 28 de dezembro de 1990. Brasília-DF: Diário O ficial da União.

Brasil 1994. M inistério da Saúde. Programa de Saúde da Família. Brasília DF.

Campos GWS 1997. Reforma da reforma, repensando a saúde. Hucitec, São Paulo.

Canesqui AM 2001. Saúde coletiva, sujeito e sociedade: comentários sobre uma proposta. Ciência \& Saúde Coletiva 6(1):24-28.

Carvalho Al 1995. Conselhos de Saúde no Brasil: participação cidadã e controle social. Ibam, Rio de Janeiro.

Conferência M unicipal de Saúde 3, 2000. Relatório. Prefeitura M unicipal de Jequié, Secretaria de Saúde.
Freire P 1979. Educação e mudança. (21ā ed.). Paz e Terra, Rio de Janeiro.

Jequié 1998, 1999, 2000 e 2001. Relatório Anual de Gestão. Secretaria M unicipal de Saúde, Jequié.

Junqueira LAP 1990. Gerência dos serviços de saúde. Cadernos de Saúde Pública 6(3):243-243.

M endes EV 1996. U ma agenda para a saúde. H ucitec, São Paulo.

M endes-Gonçalves RBM 1994. Tecnologia e organização social das práticas de saúde: características tecnológicas de processo de trabalho na rede estadual de centros de saúde de São Paulo. Hucitec, São Paulo.

M erhy EE \& Franco TB 1998. PSF: contradições e novos de safios. Conferência N acional de Saúde on-line. Disponível em <http://www.datasus.gov.br/cns>. Acesso em 30 de julho de 1999.

M erhy EE \& Franco TB 2001. Contradições de um programa destinado à mudança do modelo tecnoassistencial. São Paulo (mimeo).

Nery IG et al. 1999. Projeto de Implantação do PSF. Jequié.

Artigo apresentado em 7/11/2003

Aprovado em 27/7/2004

Versão final apresentada em 17/11/2004 